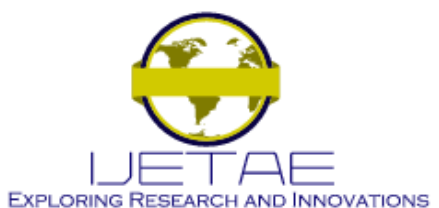

International Journal of Emerging Technology and Advanced Engineering

Website: www.ijetae.com (ISSN 2250-2459 (Online), An ISO 9001:2008 Certified Journal, Volume 3, Special Issue 1, January 2013)

International Conference on Information Systems and Computing (ICISC-2013), INDIA.

\title{
A COMPARATIVE STUDY OF THE PERFORMANCE OF PRECODED MIMO USING TRELLIS AND STBC
}

\author{
S. Dhilip Kumar ${ }^{1}$, Dr. C. Arun ${ }^{2}$ \\ ${ }^{1}$ Member IEEE;C.Arunachalaperumal, Asst Prof S.A. Eng.Coll Chennai77 \\ ${ }^{2}$ Prof. R.M.K C.E.T \\ ${ }^{1}$ Dhilip2711@yahoo.co.inche_siva@yahoo.com
}

\begin{abstract}
Spatial modulation is a transmission technique that uses multiple antennas. It involves mapping of a block of information bits to two information carrying units, as a symbol chosen from constellation diagram and a unique transmit antenna number. The importance of Spatial modulation is that it increases overall spectral efficiency. In this paper we show the performance comparison of MIMO using Trellis Coded Spatial modulation, Space Time Block Coded Spatial modulation and New Trellis Coded Spatial modulation. And performance of each coding systems yields slightly different values. TCM concept is utilized to combat performance degradation of Spatial modulation in correlated channel conditions. Whereas the STBC-SM scheme is useful for high-rate, low complexity, emerging wireless communication systems such as LTE and WiMAX. The New SM-TC scheme offers significant error performance improvements over alternatives while having a lower decoding complexity for 2,3 , and $4 \mathrm{bits} / \mathrm{s} / \mathrm{Hz}$ transmissions.
\end{abstract}

\section{INTRODUCTION}

MIMO (Multiple Input and Multiple output) systems are preferred for its high capacity, better transmission quality, increased coverage and improved user position estimation due to its Spatial multiplexing gain, diversity gain, array gain and also interference reduction. MIMO is utilized in multimedia applications, wireless internet access, Wireless last-mile systems, vehicular networks, indoor $\mathrm{WiFi}$, Optical wireless communications, Underwater communications, Radar applications.

Spatial modulation entirely avoids inter channelinterference (ICI) at the receiver input, requires no synchronization between the transmitting antennas, and avoids correlation between them while maintaining high spectral efficiency. A block of information bits is mapped into a constellation point in the signal and into the location of particular antenna (spatial domain). The receiver estimates the transmitted signal and the transmit antenna number and uses the two information to de-map the block of information bits.

\section{CHANNELMODEL}

1)Rayleigh Fading Channel: In wireless communication multipath propagation is a major issue. The effects of multipath include constructive and destructive interference, and phase shifting of the signal. This causes Rayleigh fading. Rayleigh fading is a term used when there is no direct component, and all signals are reaching the receiver are reflected.
The multipath Rayleigh fading wireless channels modeled by the channel impulse response (CIR)

$$
h(t)=\sum_{l=0}^{L p-1} \alpha_{\mathbb{l}} \partial\left(t-\tau_{R}\right)
$$

Where, $\mathrm{L}_{\mathrm{p}}$ is the number of channel paths, $\alpha_{l}$ and $\tau_{l}$ are the complex value and delay of path $l$.respectively.

2)Rician MIMO Channel:A Rician model is obtained in a system with LOS propagation and scattering. The model is characterized by the Rician factor, denoted by $\mathrm{K}$ and defined as the ratio of the line of sight and the scatter power components. The pdf for a Rician random variable $\mathrm{x}$ is given by

$p(x)=2 x(1+k) e^{-k(1+k) x^{2}} I_{0}(2 x \sqrt{k(k+1)} \quad x \geq 0$

Where

$K=\frac{D^{2}}{2 \sigma_{\dddot{\gamma}}^{2}}$

And $\mathrm{D}^{2}$ and $2 \sigma_{\%}^{2}$ are the powers of the LOS and scattered components, respectively. The powers are normalized such that

$D^{2}+2 \sigma_{\Im}^{2}=1$ 


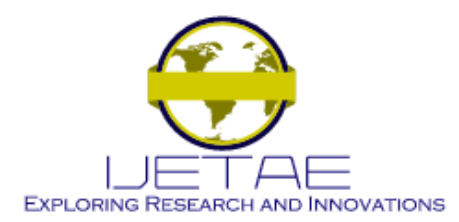

International Journal of Emerging Technology and Advanced Engineering

Website: www.ijetae.com (ISSN 2250-2459 (Online), An ISO 9001:2008 Certified Journal, Volume 3, Special Issue 1, January 2013)

International Conference on Information Systems and Computing (ICISC-2013), INDIA.

Equivalent memoryless

BSC

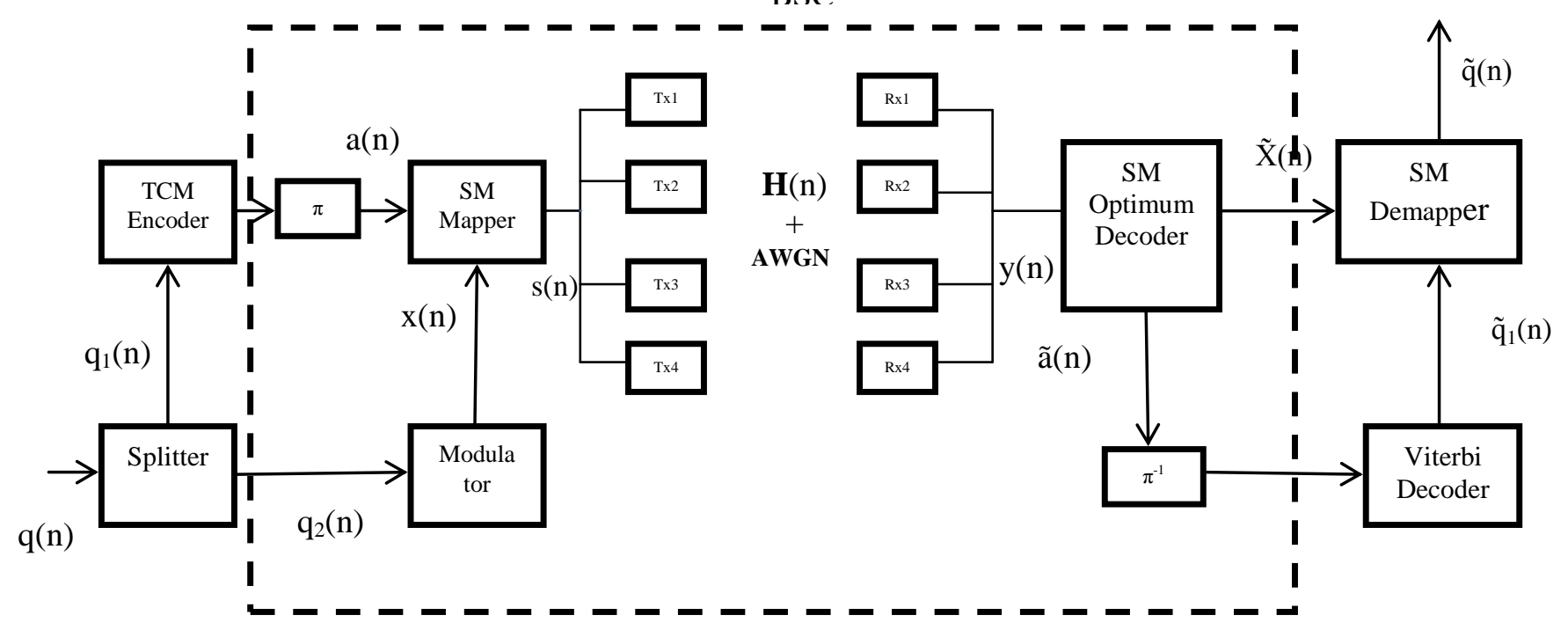

Fig. 1. Trellis coded spatial modulation (TCSM) system model.

The TCSM system model is shown in Fig. 1. A MIMO system consisting of four transmit antennas $\left(N_{t}=4\right)$ and four receive antennas $\left(\mathrm{N}_{\mathrm{r}}=4\right)$ is considered as an example.

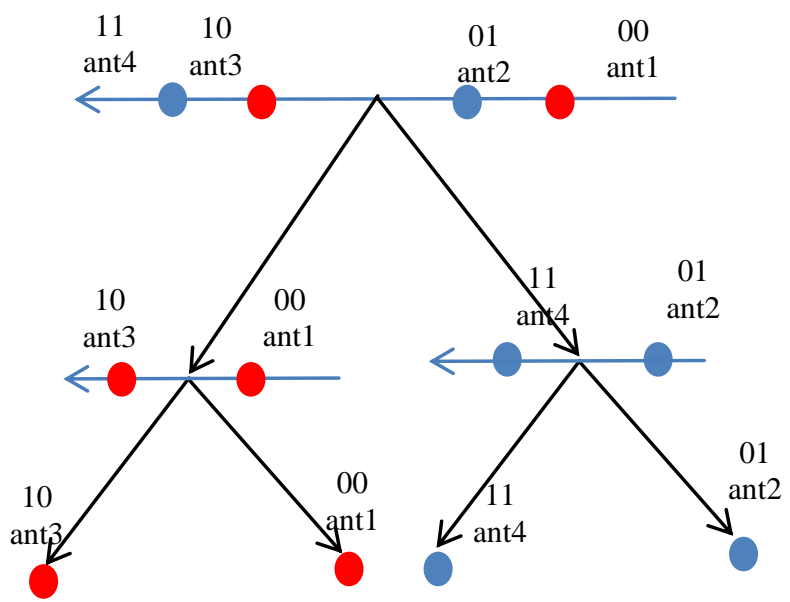

Fig. 2. TCSM Spatial constellations set partitioning.

It is depicted in the above figure, that is equal separation between the antennas is assumed. TCSM partitions the antennas into subsets. Antenna one and three form a sub-set and antennas two and four form other sub-set. Maximum separations between the antennas of each sub-set is achieved.
III. SPACE-Time Block Coded Spatial Modulation (STBC-SM)

In the STBC-SM scheme, both STBC symbols and the indices of transmit antennas from which these symbols are transmitted, carry information. Alamouti's STBC is chosen, which transmits one symbol per channel use (pcu), as the core STBC due to its advantage in terms of spectral efficiency and simplified ML detection.

\section{Table I}

STBC-SM mapping rule for $2 \mathrm{bits} / \mathrm{s} / \mathrm{Hz}$ transmission using BPSK, four transmit antennas and Alamouti's STBC

\begin{tabular}{|c|c|c|c|c|c|c|}
\hline & & $\begin{array}{c}\text { Input } \\
\text { Bits }\end{array}$ & $\begin{array}{l}\text { Transmission } \\
\text { Matrices }\end{array}$ & & $\begin{array}{l}\text { Input } \\
\text { Bits }\end{array}$ & Transmission Matrices \\
\hline \multirow{2}{*}{$\chi_{1}$} & $l=0$ & $\begin{array}{l}0000 \\
0001 \\
0010 \\
0011\end{array}$ & $\begin{array}{l}\left(\begin{array}{cccc}1 & 1 & 0 & 0 \\
-1 & 1 & 0 & 0\end{array}\right) \\
\left(\begin{array}{cccc}1 & -1 & 0 & 0 \\
1 & 1 & 0 & 0\end{array}\right) \\
\left(\begin{array}{cccc}-1 & 1 & 0 & 0 \\
-1 & -1 & 0 & 0\end{array}\right) \\
\left(\begin{array}{cccc}-1 & -1 & 0 & 0 \\
1 & -1 & 0 & 0\end{array}\right)\end{array}$ & \multirow{2}{*}{$\chi_{2}$} & $\begin{array}{l}1000 \\
1001 \\
1010 \\
1011\end{array}$ & $\begin{array}{l}\left(\begin{array}{cccc}0 & 1 & 1 & 0 \\
0 & -1 & 1 & 0\end{array}\right) e^{j \theta} \\
\left(\begin{array}{llll}0 & 1 & -1 & 0 \\
0 & 1 & 1 & 0\end{array}\right) e^{j \theta} \\
\left(\begin{array}{cccc}0 & -1 & 1 & 0 \\
0 & -1 & -1 & 0\end{array}\right) e^{j \theta} \\
\left(\begin{array}{cccc}0 & -1 & -1 & 0 \\
0 & 1 & -1 & 0\end{array}\right) e^{j \theta}\end{array}$ \\
\hline & $l=1$ & $\begin{array}{l}0100 \\
0101 \\
0110\end{array}$ & $\begin{array}{l}\left(\begin{array}{lllc}0 & 0 & 1 & 1 \\
0 & 0 & -1 & 1\end{array}\right) \\
\left(\begin{array}{lllc}0 & 0 & 1 & -1 \\
0 & 0 & 1 & 1\end{array}\right) \\
\left(\begin{array}{lllc}0 & 0 & -1 & 1 \\
0 & 0 & -1 & -1\end{array}\right) \\
\left(\begin{array}{llll}0 & 0 & -1 & -1 \\
0 & 0 & 1 & -1\end{array}\right)\end{array}$ & & $\begin{array}{l}1100 \\
1101 \\
1110\end{array}$ & $\begin{array}{l}\left(\begin{array}{cccc}1 & 0 & 0 & 1 \\
1 & 0 & 0 & -1\end{array}\right) e^{j \theta} \\
\left(\begin{array}{cccc}-1 & 0 & 0 & 1 \\
1 & 0 & 0 & 1\end{array}\right) e^{j \theta} \\
\left(\begin{array}{cccc}1 & 0 & 0 & -1 \\
-1 & 0 & 0 & -1\end{array}\right) e^{j \theta} \\
\left(\begin{array}{cccc}-1 & 0 & 0 & -1 \\
-1 & 0 & 0 & 0\end{array}\right) e^{j \theta}\end{array}$ \\
\hline
\end{tabular}




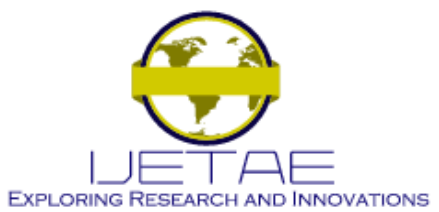

International Journal of Emerging Technology and Advanced Engineering

Website: www.ijetae.com (ISSN 2250-2459 (Online), An ISO 9001:2008 Certified Journal, Volume 3, Special Issue 1, January 2013)

\section{International Conference on Information Systems and Computing (ICISC-2013), INDIA.}

In table 1 , the first two information bits $\left(u_{1}, u_{2}\right)$ are used to determine the antenna pair position $l$ while the last two $\left(u_{3}, u_{4}\right)$ determine the BPSK symbol pair.

\section{New Trellis Code Design For Spatial MODULATION}

The considered SM-TC system model is shown in Fig.. The independent and identically distributed (i.i.d.) binary information sequence $\mathrm{u}$ is encoded by a rate $R=$ $k / n$ trellis (convolutional) encoder whose output sequence $\mathrm{v}$ enters the SM mapper. The spatial modulator is designed inconjunction with the trellis encoder to transmit $n$ coded bits in a transmission interval by means ofthe symbols selected from an $M$-level signal constellation such as $M$-ary phase-shift keying ( $M$-PSK), $M$-ary quadrature amplitude modulation ( $M$-QAM), etc., and of the antenna selected from a set of $n_{t}$ transmit antennas such that $n=\log 2\left(M n_{T}\right)$.

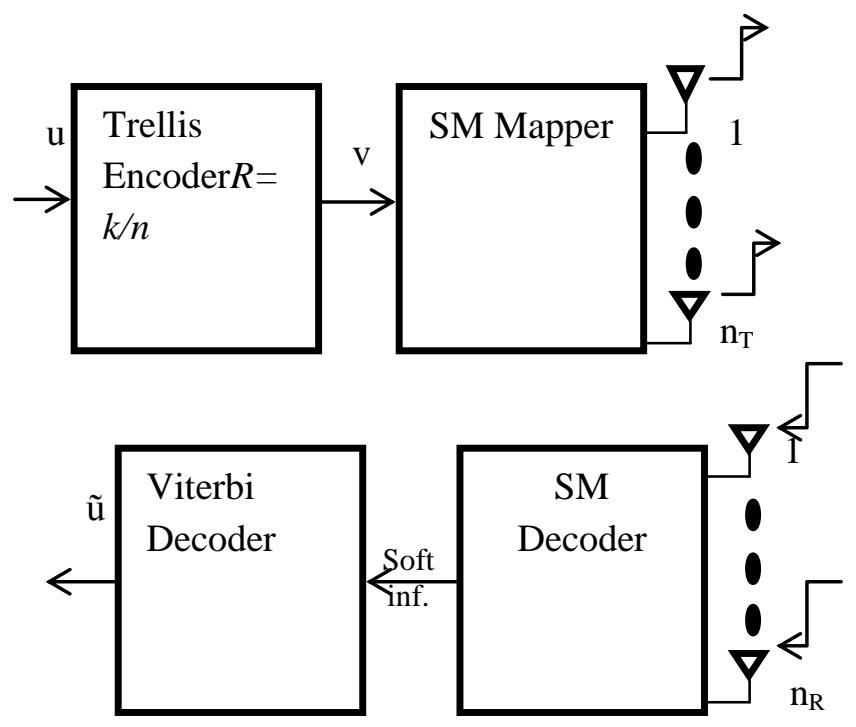

Fig.3.SM-TC system model
$0000 /(1,0) 0010 /(1,2) 0100 /(2,0) 0110 /(2,0)$

$1000 /(3,0) 1010 /(3,2) 1100 /(4,0) 1110 /(4,2)$

$0101 /(2,1) 0111 /(2,3) 0001 /(1,1) 0011 /(1,3)$

$1101 /(1,0) 1111 /(4,3) 1001 /(3,1) 1011 /(3,3)$
00

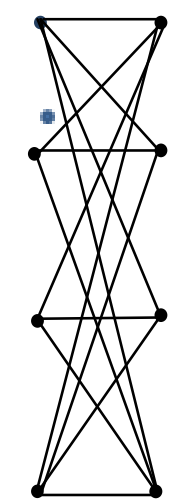

Fig.4. Trellis diagram of the SM-TC scheme with $R=2 / 4$ trellis encoder,four transmit antennas and QPSK symbols given by $\exp (2 \pi s / 4)$.

\section{Simulation Results And COMPARISONS}

In this section, we present simulation results for the SM, SM-TC and TCSM with different configurations. At first SM with uncorrelated $(r=0)$ and with correlated $(\mathrm{r}=0.7)$ are simulated. Similarly SMTC respectively simulated. And Comparisons of SM and TCSM are made in ideal channel and Rician fading channel. Also SM and STBC-SM plots are simulated.

\section{A. Comparison of SM and STBC-SM}

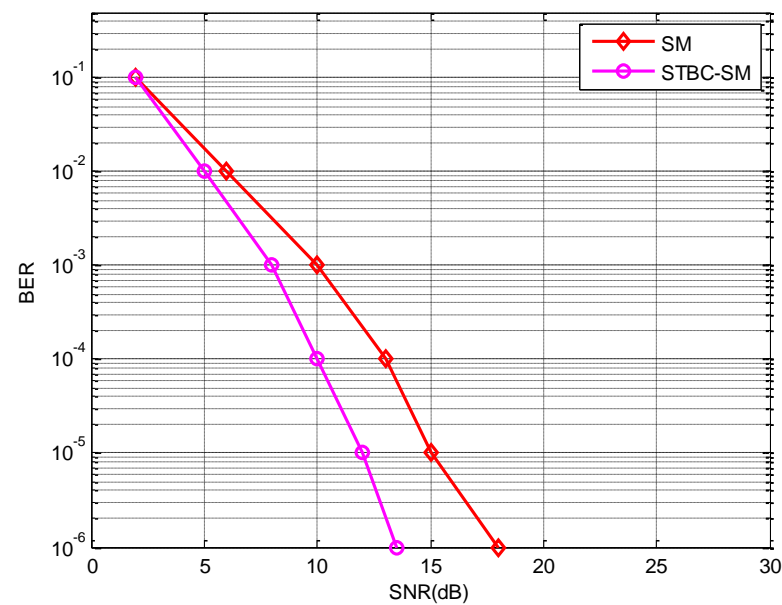

Fig .5. BER performance at 4 bits/s/Hz for STBC-SM and SM 


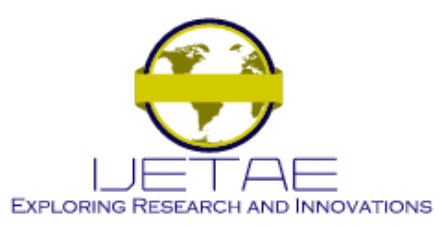

International Journal of Emerging Technology and Advanced Engineering

Website: www.ijetae.com (ISSN 2250-2459 (Online), An ISO 9001:2008 Certified Journal, Volume 3, Special Issue 1, January 2013)

International Conference on Information Systems and Computing (ICISC-2013), INDIA.

In the above graph it is clear that STBC-SM provides SNR gains $3.5 \mathrm{~dB}$ over SM. We conclude from this result that one can optimize the error performance without expanding the spatial constellation to improve spectral efficiency.

\section{B. Comparison of SM and TCSM}

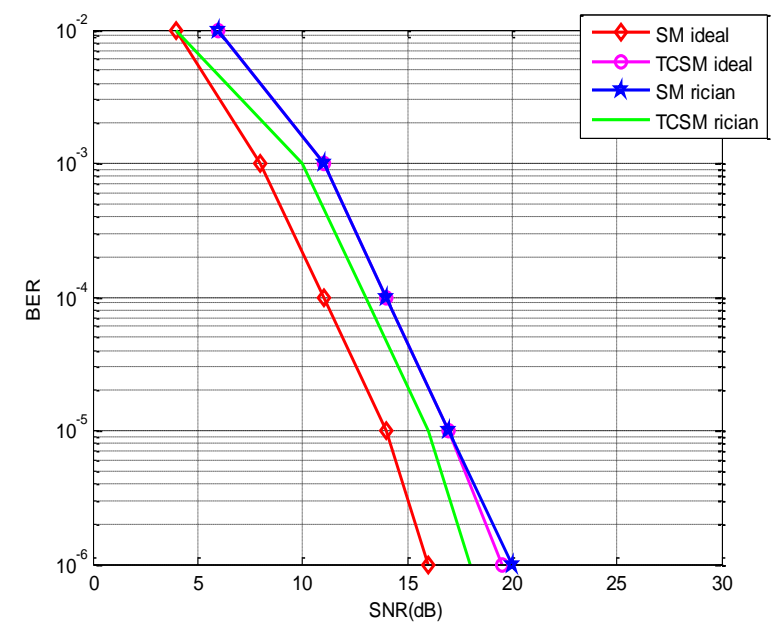

Fig. 6.Performance comparison of SM $4 \times 4$ BPSK and TCSM $4 \times 4$ QAM in ideal and rician channel.

It is seen that in Ideal conditions uncoded SM systems outperforms all other systems. SM outperforms the TCSM system by about $3 \mathrm{~dB}$. However, the situation is different if correlated channel paths are considered i.e., when rician fading channels are considered. The TCSM outperforms in the range of SNR[2]. The advantages of TCSM over all other schemes is obvious in Fig.6.

\section{Comparison of SM and SMTC(New Trellis Code)}

The Graph shows BER of a Spatial modulation MIMO scheme for different scenarios. It is noticed that spatial modulation with trellis coding has outperformed conventional spatial modulation scheme.

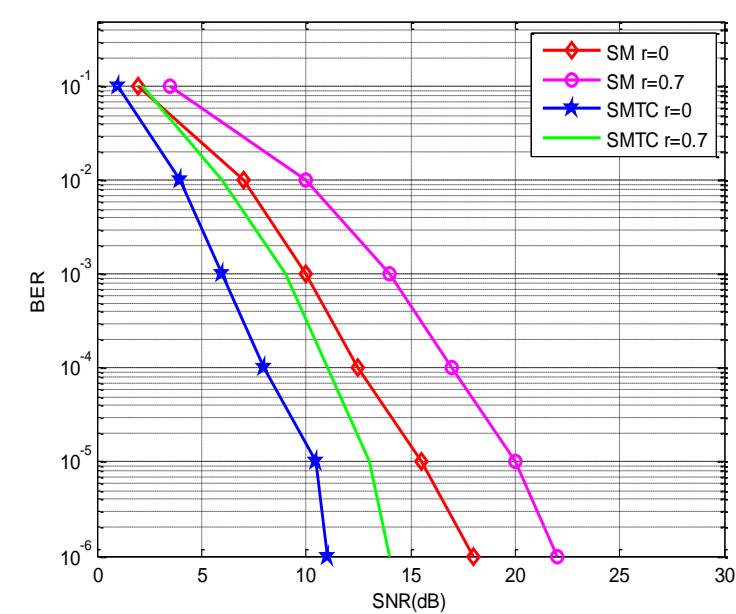

Fig. 7. BER Comparison at 4 bits/Hz for uncorrelated and correlated channels.

In conventional Spatial modulation also with respect to the $r$ value there is a notable improvement i.e as the $r$ value increases the BER performance degrades.

The same scenario is also observed for SMTC for $r=0$ at a cost of $11 \mathrm{~dB}$ SNR we could able to get the BER of $10^{-6}$. But for $r=0.7$ the same performance is obtained at the cost of $14 \mathrm{~dB}[3]$. So from the above illustration we may concluded SMTC with higher value of $r$ is given better performance which is very much need for wireless communication system.

\section{CONCLUSION}

It has been shown via computer simulations and also supported by a theoretical upper bound analysis that STBC-SM offers significant advantages in BER compared V-BLAST and SM systems. And the performance of TCSM has been simulated in several channel conditions and compared to MIMO systems. It has been shown that a major enhancement in SNR can be obtained in Rician fading and correlated channel conditions. At last it is shown a novel coded MIMO transmission scheme that combines trellis coding and SM. And it shows significant error performance improvements than other schemes. 


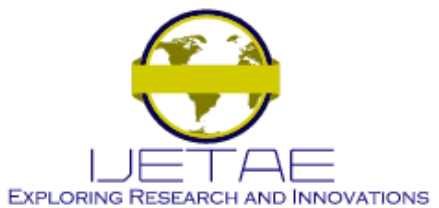

International Journal of Emerging Technology and Advanced Engineering

Website: www.ijetae.com (ISSN 2250-2459 (Online), An ISO 9001:2008 Certified Journal, Volume 3, Special Issue 1, January 2013)

\section{International Conference on Information Systems and Computing (ICISC-2013), INDIA.}

\section{REFERENCES}

[1] E. Bas,ar, U”. Aygo"lu", E. Panayırc1, and H. V. Poor, "Spacetime blockcoded spatial modulation," IEEE Trans. Commun., vol. 59, no. 3, pp.823-832, Mar. 2011.

[2 ] R. Mesleh, M. D. Renzo, H. Haas, and P. M. Grant, "Trellis coded spatial modulation," IEEE Trans. Wireless Commun., vol. 9, no. 7, pp. 2349-2361, July 2010.

[3 ] Ertug rulBas, ar, U“mitAygo“lu“,ErdalPanayırc1 H. Vincent Poor, "New Trellis Code Design for Spatial Modulation, IEEE Trans. Wireless Commun.1536-1276/11 2011 IEEE.(accepted for Publication)
[4] P. Wolniansky, G. Foschini, G. Golden, and R. Valenzuela, "VBLAST:an architecture for realizing very high data rates over the rich-scatteringwireless channel," in Proc. URSI Int. Symp. Signals, Systems, Electronics,pp. 295-300, Sep. 1998.

[5 ] R. Mesleh, H. Haas, C. W. Ahn, and S. Yun, "Spatial modulationa new low complexity spectral efficiency enhancing technique," in Proc. Conf. Commun. and Networking in China, pp. 1-5, Oct. 2006.

[6] R. Mesleh, H. Haas, S. Sinanovic, C. W. Ahn, and S. Yun, "Spatialmodulation," IEEE Trans. Veh. Technol., vol. 57, no. 4, pp. 2228-2241,July 2008 